\title{
Signs and Symptoms of Impending Death in End-of-life Elderly Dementia Sufferers: Point of View of Formal Caregivers in Rural Areas -A Qualitative Study-
}

\author{
Yoshihisa Hirakawa and Kazumasa Uemura \\ Center for Postgraduate Clinical Training and Career Development, Nagoya University Hospital, Japan
}

\begin{abstract}
Objective: The aim of the present study was to clarify the signs and symptoms of impending death in end-of-life senile dementia from the point of view of formal caregivers in rural areas.

Patient/Materials and Methods: We used qualitative data based on retrospective analyses. The data was gathered following a workshop on end-of-life care of the elderly with dementia attended by formal caregivers that was held in Iga City, Mie Prefecture, Japan, in September 2011. There was a total of 29 workshop participants. The workshop products were created in the first session of the workshop entitled "Signs of death." During the session, we used the brainstorming method, and participants took turns stating at least two signs, symptoms or premonitions of death. In the end, there were 93 cards in total displaying signs of impending death observed in the end stage of dementia. These 93 entries were then classified into clear categories.

Results: The categories defined were breathing disorder, consciousness decline, vital power decline, reduced oral intake, feces disorder, calm and peaceful character, blood pressure decline, change in skin color, patient odor, edema, preagonal vital power, body temperature decline, bedsore/wound deterioration, body weight reduction, cyanosis, and oliguria. The most frequently cited symptoms fell in the breathing disorder category (12 cards), followed by consciousness decline ( 9 cards), vital power decline ( 9 cards), reduced oral intake (6 cards), and feces disorder ( 6 cards). Also frequently mentioned were symptoms falling in the calm and peaceful character, patient odor and preagonal vital power categories.

Conclusion: The results show that formal caregivers in rural areas identified breathing disorder as a top indicator of impending death in end-of-life senile dementia cases. The results also highlight some other characteristic signs of impending death, such as preagonal
\end{abstract}

Correspondence to: Yoshihisa Hirakawa, Center for Postgraduate Clinical Training and Career Development, Nagoya University Hospital, 65 Tsuruma-cho, Showa-ku, Nagoya City, Aichi 466-8560, Japan E-mail: y.hirakawa@med.nagoya-u.ac.jp vital power and calm and peaceful character. This research could help develop formal caregivers' observational skills in the end-oflife care settings.

Key words: dementia, symptom, end-of-life, qualitative study, formal caregiver

(J Rural Med 2012; 7(2): 59-64)

\section{Introduction}

It is generally believed that, in Japan, elderly people would rather pass away at a long-term care facility or in the home where they have spent most of their life, although in recent years, a growing number of Japanese people spend their last days of life in hospitals ${ }^{1,2)}$. However, hospitals no longer have the spare bed capacity to cope with the increasing demands of an aging population ${ }^{1)}$. Therefore, institutional and home end-of-life care for the elderly has received much attention in Japan, especially in rural areas, where there has been a dramatic rise in elderly patients and a serious shortage of hospital physicians ${ }^{3}$. In community settings, such as long-term care facilities or the home, the role of formal caregivers is more significant in end-of-life care of the elderly than in hospitals ${ }^{4,5}$. Formal caregivers also develop a closer relationship with dying patients and their families than hospital staff. Moreover, in cooperation with family members, formal caregivers are required to prepare for death and to notify local medical services of any sudden change in the patients' condition. As a result, they inevitably need to deepen their understanding of the signs and symptoms of advanced dementia through education.

The main diseases of aged people in end-of-life care are cancer, dementia, and internal organ failure ${ }^{6}$. Literature on the pain and suffering of aged cancer sufferers is widely 
available $^{7-10)}$. The research shows the following dominant signs and symptoms: loss of appetite, pain, whole body malaise, dyspnea, fever, edema, coma, delirium, pleural effusion and ascites.

However, further research on the signs and symptoms of advanced dementia in the elderly is necessary, especially in light of the fact that end-of-life dementia is increasing, particularly in recent years due to the sharp rise in the aging population $^{11-13)}$. Research on the topic is truly lacking, and relevant data has not yet been adequately collected ${ }^{13)}$. This is in part because it is difficult to garner clear indications of the signs and symptoms from elderly people who suffer from dementia due to their impaired and lowered communication and cognition skills ${ }^{13-15}$. Also, there may be a lack of acknowledgment and understanding among nonmedical professionals that dementia is a syndrome causing death ${ }^{14,16,17)}$. This is actually a reflection of the opinions of medical professionals who have a strong influence on nonmedical professionals.

Moreover, those caregivers that are at the forefront of end-of-life care of dementia sufferers are not always accustomed to medical terminology, and as a result, their observations may differ from the opinions of physicians and nurses. Thus, we recognize the need for the opinions of formal caregivers regarding the symptoms and signs of impending death of elderly people suffering from end-of-life dementia to be formulated clearly. Therefore, the present study aims at clarifying the signs and symptoms of impending death in end-of-life senile dementia from the point of view of formal caregivers.

\section{Materials and Methods}

Formal caregivers are defined as paid nonmedical care providers (including certified care workers) from a private agency or a government or nonprofit organization in the present study. We used qualitative data based on retrospective analyses. The data was gathered following a workshop on end-of-life care of the elderly with dementia attended by formal caregivers that was held in Iga City, Mie Prefecture, Japan, in September 2011. The workshop was entitled "Thinking about Dementia Palliative Care and Behavioral and Psychological Symptoms of Dementia (BPSD)." Iga City, which located in the northwestern part of Mie Prefecture, has a population of 100,000 . The city is in a typical rural area, roughly positioned between Osaka and Nagoya. About $27 \%$ of the people in Iga are over 65 years of age. Workshop participants were selected with the help of the social welfare council office of Iga City from a wide range of people involved in caregiving. Iga suffers from an acute shortage of hospital physicians, and we therefore believed that the workshop products would be very instructive, since many caregivers experienced with end-of-life care outside the hospital would contribute to the research. We also believed that there would be many caregivers in this area with bedside experience of death from dementia. These are the main reasons why our research was based in Iga City. There were 29 workshop participants in total. The average age of the participants was 46.9 years old. There were 24 female and 5 male participants. Eighteen people held administrative positions in their workplaces.

The workshop products were created in the first session of the workshop entitled "Signs of death." During the session, the participants were divided into smaller groups of 7 to 8 people. We used the brainstorming method in the session. Because brainstorming works best with a varied group of people, each group consisted of participants who came from various departments across the organization. The rules of brainstorming were "focus on quantity," "withhold criticism," "welcome unusual ideas" and "combine and improve ideas." Also, to stimulate idea generation, the participants were required to take turns stating at least one sign, symptom or premonition of death. This continued until no participants had any original ideas, and at least two signs, symptoms or premonitions of death were required per person. Each group elected a record keeper, who made a list of all signs, symptoms or premonitions of death stated in each group.

The workshop products were analyzed in December 2011. First, we transferred all the signs, symptoms or premonitions of death from the lists given by each group to individual cards, for a total of 89 cards. Next, in cases where more than two symptoms were listed on a single card, we separated the symptoms and listed them on separate cards. For instance, we had cards for "hypothermia/hypotension," "melena/hematemesis," "hallucination/twilight state" and "no reduction in fever/pneumonia," which we subsequently listed individually on 8 cards. In the end, there were 93 cards in total displaying signs of impending death observed at the end stage of dementia.

These 93 entries were then classified into clear categories by the head author of this report and 3 assistant researchers familiar with the purpose of the research. This was accomplished by the head author reading out the cards one by one and then the assistant researchers grouping the cards, which were laid out in front of them, together with other cards that looked like they belonged with them. The head author and the 3 assistant researchers discussed the groupings and then gave them an appropriate title. Effort was made to avoid technical terms so as to allow caregivers to relate to them quickly. Careful consideration was also taken not to adhere to the usual preconceptions, ensuring a fresh approach to the research topic. Furthermore, we listed 
separately a number of symptoms that did not fit into any of the outlined categories. These "solitary cards" were not excluded from the research but were classified as separate entries. Finally, we reviewed the entries in each category carefully until we reached a consensus among our research team members. This research was carried out with the consent of the Nagoya University School of Medicine Ethics Committee (Approval number 82).

\section{Results}

The cards were numbered and collated according to category. Table 1 lists the various categories and symptoms listed on the cards. The categories defined were breathing disorder, consciousness decline, vital power decline, reduced oral intake, feces disorder, calm and peaceful character, blood pressure decline, change in skin color, patient odor, edema, preagonal vital power, body temperature decline, bedsore/wound deterioration, body weight reduction, cyanosis and oliguria. The most frequently cited symptoms fell in the breathing disorder category (12 cards), followed by consciousness decline ( 9 cards), vital power decline ( 9 cards), reduced oral intake (6 cards) and feces disorder (6 cards). Also frequently mentioned were symptoms falling in the calm and peaceful character, patient odor and preagonal vital power categories. Other symptoms such as ascites and presence of water in the lungs that did not fit into other categories were listed in the solitary cards category. Other symptoms difficult to classify such as family members become kinder and get along better with family, whose interpretations are difficult to ascertain, were also placed in the solitary cards category, since they were related to the theme of this research.

\section{Discussion}

This research has an original approach to its topic, in that it attempts to clarify the signs and symptoms of death in end-of-life dementia cases from the point of view of formal caregivers in rural areas. Since the setting of the research was limited to a single rural area in Mie Prefecture, Japan, care needs to be taken regarding the interpretation and generalization of the results; nevertheless, we believe that this research could help develop formal caregivers' observational skills in the end-of-life care settings.

The results show that caregivers in rural areas identified symptoms falling into the breathing disorder category with the greatest frequency, confirming it as a top indicator of impending death. Dyspnea was sometimes expressed as breathing hard, panting and shoulder breathing, and breathing pattern disorders were described as lower jaw breathing.
These symptoms are widely observed in end-of-life patients with cancer, dementia and internal organ failure.

However, regarding breathing pattern disorders, various classifications exist, such as Cheyne-Stokes breathing, Biot's breathing and lower jaw breathing. Because each breathing disorder has different causes, caregivers should be able to identify breathing disorders more accurately. Caregivers need to acquire the medical knowledge about breathing patterns and observation points.

Other symptoms falling in the categories of consciousness decline, vital power decline and reduced oral intake were frequently observed among end-of-life dementia elderly in formal daily care settings ${ }^{16)}$. It is widely known that daily life actions, volition and swallowing abilities decline as dementia progresses ${ }^{16)}$. Formal caregivers easily recognized reduced oral intake symptoms as signs of impending death.

Regarding feces disorder, a unique symptom, the Japanese word kanibaba means meconium but is also known by the general public as death-bed feces. Tarry feces and bloody feces are symptoms that commonly appear in the end-of-life phase ${ }^{18)}$, but they can also appear in curable cases such as peptic ulcer. Therefore, they should not necessarily be associated with impending death.

The calm and peaceful character category was considered to provide new insight into the research topic. Although prior research indicates that BPSD such as hallucination, anxiety, irritation and shouting loudly are commonly observed among end-of-life dementia patients ${ }^{16)}$, there is hardly any documented reference on mood improvement. It is possible that this could be a distinct sign of impending death in elderly people with senile dementia.

Regarding the preagonal vital power category, we think that this is the same condition that Barbara Karnes describes in her publication ${ }^{19}$, referring to terminal cancer patients who become temporarily active a few days before death. Our results suggest the possibility that the same symptom appears in cases of elderly people with senile dementia, but there is a lack of sufficient corroborative research to confirm this. Further research on this topic is therefore needed.

A number of caregivers mentioned odor as a foreboding symptom of death, especially the smell of a dead body. In dementia end-of-life cases, daily-life independence declines gradually; incontinence usually happens as a result of cognitive function decline, causing a foul smell in elderly people's living environments. Patient odor in places where the elderly are cared for has been well documented in literature ${ }^{1,20)}$. As far as we know, however, the particular smell of a dead body-the odor that the dead body gives offhas not been documented. It is possible that the workshop participants assumed that the smell of a dead body meant 
Table 1 Signs and symptoms at the end stage of dementia listed by formal caregivers

\begin{tabular}{|c|c|}
\hline $\begin{array}{c}\text { Category } \\
\text { (number of cards) }\end{array}$ & $\begin{array}{l}\text { List of words written on cards } \\
\text { (number of cards) }\end{array}$ \\
\hline Breathing disorder (12) & $\begin{array}{l}\text { breathing hard (2) } \\
\text { deep breathing } \\
\text { increased state of apnea } \\
\text { increased yawning } \\
\text { keeping mouth open } \\
\text { longer state of apnea } \\
\text { lower jaw breathing (2) } \\
\text { panting (2) } \\
\text { shoulder breathing }\end{array}$ \\
\hline Consciousness decline (9) & $\begin{array}{l}\text { decreased vital reaction } \\
\text { fall into delirium } \\
\text { loss of consciousness } \\
\text { not responding (2) } \\
\text { slower to react } \\
\text { slow to respond } \\
\text { twilight state (2) }\end{array}$ \\
\hline Vital power decline (9) & $\begin{array}{l}\text { cannot talk } \\
\text { do not talk } \\
\text { increased sleep time } \\
\text { loss of desire } \\
\text { more frequently somnolent } \\
\text { no movement } \\
\text { no longer act violently } \\
\text { no conversation } \\
\text { sleep longer }\end{array}$ \\
\hline Reduced oral intake (6) & $\begin{array}{l}\text { anorexia } \\
\text { cannot eat } \\
\text { cannot eat from mouth } \\
\text { cannot even take water } \\
\text { cannot take water }(2)\end{array}$ \\
\hline Feces disorder (6) & $\begin{array}{l}\text { appearance of black feces } \\
\text { kanibaba** } \\
\text { melena } \\
\text { tarry feces (3) }\end{array}$ \\
\hline $\begin{array}{l}\text { Calm and peaceful charac- } \\
\text { ter (5) }\end{array}$ & $\begin{array}{l}\text { become gentle, obedient } \\
\text { change from obstinate to calm and ap- } \\
\text { preciative } \\
\text { express thanks } \\
\text { put affairs in order } \\
\text { suddenly become gentle }\end{array}$ \\
\hline Blood pressure decline (5) & $\begin{array}{l}\text { blood pressure cannot be measured } \\
\text { blood pressure decline } \\
\text { decline in blood pressure } \\
\text { decline in blood pressure/impossible to } \\
\text { measure } \\
\text { hypotension }\end{array}$ \\
\hline
\end{tabular}

Table 1 (continued)

\begin{tabular}{|c|c|}
\hline $\begin{array}{c}\text { Category } \\
\text { (number of cards) }\end{array}$ & $\begin{array}{l}\text { List of words written on cards } \\
\text { (number of cards) }\end{array}$ \\
\hline Change in skin color (4) & $\begin{array}{l}\text { skin becomes deadly pale/earth-like } \\
\text { color } \\
\text { skin color changes } \\
\text { skin color drains/turns white } \\
\text { skin turns pale }\end{array}$ \\
\hline Patient odor (4) & $\begin{array}{l}\text { exude dead body smell (2) } \\
\text { exude sour smell } \\
\text { terrible smell }\end{array}$ \\
\hline Edema (4) & $\begin{array}{l}\text { begin to swell } \\
\text { edema of extremities } \\
\text { edema of instep } \\
\text { edema of underside of foot }\end{array}$ \\
\hline Preagonal vital power (3) & $\begin{array}{l}\text { flash of vigor/last flame? } \\
\text { more talkative } \\
\text { sudden appetite improvement }\end{array}$ \\
\hline $\begin{array}{l}\text { Body temperature decline } \\
\text { (3) }\end{array}$ & $\begin{array}{l}\text { body becomes cold/hypothermia } \\
\text { body temperature decline } \\
\text { hypothermia }\end{array}$ \\
\hline $\begin{array}{l}\text { Bedsore/wound deteriora- } \\
\text { tion (3) }\end{array}$ & $\begin{array}{l}\text { bedsores get worse } \\
\text { presence of bedsores } \\
\text { wounds do not heal }\end{array}$ \\
\hline Body weight reduction (2) & weight loss (2) \\
\hline Cyanosis (2) & $\begin{array}{l}\text { blood flow to the distal end of the body } \\
\text { blocked/becomes purple } \\
\text { legs become cold }\end{array}$ \\
\hline Oliguria (2) & $\begin{array}{l}\text { difficulty passing urine } \\
\text { oliguria }\end{array}$ \\
\hline Solitary cards (14) & $\begin{array}{l}\text { ascites } \\
\text { bradycardia } \\
\text { chocolate-colored phlegm } \\
\text { constant fever } \\
\text { family members become kind } \\
\text { feel lonely and call their family } \\
\text { get along better with family } \\
\text { hallucinate } \\
\text { hematemesis } \\
\text { incontinence } \\
\text { lips round and thoroughly dried out } \\
\text { pneumonia } \\
\text { presence of water in lungs } \\
\text { pupillary dilation }\end{array}$ \\
\hline
\end{tabular}

* The head author and assistant researchers classified the cards and gave all appropriate title to the groups. ** The responses of the formal caregivers are listed in alphabetical order. $* * *$ Kanibaba means death-bed feces in the text. 
that the body's odor undergoes a transition just before death. Understandably, both the smell of feces and the smell of a dead body exert a negative influence on comfortable bedside care surroundings. For a better outlook on this issue, further research about odor in elderly care locations needs to be carried out.

Body weight reduction is often observed among the elderly with end-of-life dementia ${ }^{21}$. In fact, a previous study emphasizes the deep factor connection between body weight reduction and the prognosis of elderly patients ${ }^{22}$. At the dementia end-of-life stage, even if the appropriate amounts of nutrition are given, body-weight reduction still occurs ${ }^{23}$.

Our study has a number of important limitations. First, because our study was retrospective in nature, we were unable to ascertain the places of employment of the participants, such as elderly nursing homes or home care settings, which may have been unevenly balanced. Second, there is a high possibility that the symptoms at end-of-life vary depending on where the elderly people are taken care of, and we therefore think that further investigation is warranted, with a narrower focus on the attributes of the target group, such as research targeting long-term care facility caregivers. Third, in this research, a number of typical symptoms were not mentioned, such as death rattle, that appear at the time of death. For a more objective interpretation of the results, we think it is necessary to do additional research with an increased number of participants and number of issues.

\section{Conclusions}

This research had the original approach of clarifying the signs and symptoms of death in end-of-life senile dementia cases from the point of view of caregivers in rural areas. The results show that caregivers in rural areas identified breathing disorder as a top indicator of impending death. The results also highlight some other characteristic signs of impending death in end-of-life senile dementia cases, such as preagonal vital power and calm and peaceful character. This research could help develop formal caregivers' observational skills in the end-of-life care settings.

\section{Acknowledgment}

This study was supported by a grant from the Sasagawa Memorial Health Foundation. We declare that we have no conflicts of interest.

\section{References}

1. Hirakawa Y. Palliative care for the elderly: a Japanese perspective. In: Contemporary and Innovative Practice in Pallia- tive Care. Chang E, Johnson A, Eds. InTech, 2012; Available from: http://www.intechopen.com/articles/show/title/palliative-care-for-the-elderly-a-japanese-perspective.

2. Hirakawa Y, Masuda Y, Uemura K, et al. End-of-life care at group homes for patients with dementia in Japan -findings from the analysis of policy-related differences. Arch Gerontol Geriatr 2006; 42: 233-245. [Medline]

3. Matsumoto M, Inoue K, Kajii E, et al. Retention of physicians in rural Japan: concerted efforts of the government, prefectures, municipalities and medical schools. Rural Remote Health 2010; 10: 1432 (online); Available from: http://www. rrh.org.au. [Medline]

4. Hirakawa Y. End-of-life care at long-term care facilities for the elderly in Japan. Hallym International Journal of Aging (HIJA) 2009; 11: 1-12.

5. Hirakawa Y, Kuzuya M, Uemura K. Opinion survey of nursing or caring staff at long-term care facilities about end-oflife care provision and staff education. Arch Gerontol Geriatr 2009; 49: 43-48. [Medline]

6. Lunney JR, Lynn J, Foley DJ, et al. Patterns of functional decline at the end of life. JAMA 2003; 289: 2387-2392. [Medline]

7. Twycross RG. The terminal care of patients with lung cancer. Postgrad Med J 1973; 49: 732-737. [Medline]

8. van den Beuken-van Everdingen MH, de Rijke JM, Kessels AG, et al. Prevalence of pain in patients with cancer: a systematic review of the past 40 years. Ann Oncol 2007; 18: 1437-1449. [Medline]

9. Hirakawa Y, Masuda Y, Kuzuya M, et al. Symptoms and care of elderly dying at home with lung, gastric, colon, and liver cancer. Jpn Med Assoc J 2006; 49: 140-145 (JMAJ).

10. Morita T, Tsunoda J, Inoue S, et al. Characteristics of palliative care for elderly cancer patients -a pilot study at our hospital. Geriat Med 1997; 35: 1505-1511 (in Japanese).

11. Morrison RS, Siu AL. Survival in end-stage dementia following acute illness. JAMA 2000; 284: 47-52. [Medline]

12. Sampson EL, Ritchie CW, Lai R, et al. A systematic review of the scientific evidence for the efficacy of a palliative care approach in advanced dementia. Int Psychogeriatr 2005; 17: 31-40. [Medline]

13. Hirakawa Y, Masuda Y, Kuzuya M, et al. End-of-life experience of demented elderly patients at home: findings from DEATH project. Psychogeriatrics 2006; 6: 60-67.

14. Hirakawa Y, Masuda Y, Kimata T, et al. Terminal care for elderly patients with dementia in two long-term care hospitals. Nihon Ronen Igakkai Zasshi 2004; 41: 99-104 (in Japanese, Abstract in English). [Medline]

15. Scherder E, Herr K, Pickering G, et al. Pain in dementia. Pain 2009; 145: 276-278. [Medline]

16. Sampson EL. Palliative care for people with dementia. $\mathrm{Br}$ Med Bull 2010; 96: 159-174. [Medline]

17. Sachs GA, Shega JW, Cox-Hayley D. Barriers to excellent end-of-life care for patients. J Gen Intern Med 2004; 19: 1057-1063. [Medline]

18. Kuebler KK, Berry PH, Heidrich DE. End-of-life Care: Clini- 
cal Practice Guidelines. Berry PH, Heidrich DE, Eds. W.B. Saunders, Philadelphia, 2002.

19. Karnes B. Gone from My Sight -the Dying Experience. Barbara Karnes Books, Vancouver, 2008.

20. Hirakawa Y, Suzuki S, Uemura K. Trial to use persimmon leaf tea as air freshener at a long-term care facility. Hospice and Home Care 2010; 18: 53-55 (in Japanese).

21. Henderson ML, Hanson LC, Reynolds KS. Improving Nursing Home Care of the Dying: a Training Manual for Nursing
Home Staff. Springer, New York, 2003.

22. Flacker JM, Kiely DK. A practical approach to identifying mortality-related factors in established long-term care residents. J Am Geriatr Soc 1998; 46: 1012-1015. [Medline]

23. Palliative CDI. Enhancing Community Capacity Project. Dementia: Information for Carers, Families and Friends of People with Severe and End Stage Dementia. 2nd ed. University of Western Sydney, Penrith South, 2007. 